\title{
LAU-0901, a novel platelet-activating factor antagonist, is highly neuroprotective in cerebral ischemia
}

\author{
Ludmila Belayev $^{a, *}$, Larissa Khoutorova ${ }^{a}$, Kristal Atkins ${ }^{a}$, William C. Gordon ${ }^{\text {a }}$, \\ Julio Alvarez-Builla ${ }^{\mathrm{b}}$, Nicolas G. Bazan ${ }^{\mathrm{a}}$ \\ a Neuroscience Center of Excellence, School of Medicine, Louisiana State University Health Sciences Center, New Orleans, LA 70112, USA \\ b Depto. de Químíca Organica, Universidad de Alcala, 28871, Alcala de Henares, Madrid, Spain
}

\section{A R T I C L E I N F O}

\section{Article history:}

Received 20 June 2008

Revised 12 August 2008

Accepted 14 August 2008

Available online 28 August 2008

\section{Keywords:}

LAU-0901

PAF antagonist

Middle cerebral artery occlusion

Behavioral

Histopathology

Local cerebral blood flow

\begin{abstract}
A B S T R A C T
Platelet-activating factor (PAF) is a bioactive phospholipid that accumulates during ischemia-reperfusion and is involved in the activation of platelets, neutrophils, and pro-inflammatory signaling. PAF has been suggested to enhance brain ischemia-reperfusion damage. LAU-0901, a novel PAF receptor antagonist, was examined in models of focal cerebral ischemia in rats and mice. Sprague-Dawley rats were anesthetized and received 2hour middle cerebral artery occlusion (MCAo) by intraluminal suture. LAU-0901 (30,60, $90 \mathrm{mg} / \mathrm{kg} ; n=9-11)$ or vehicle $(n=11)$ was administered i.p. at $2 \mathrm{~h}$ after onset of MCAo. The neurological status was evaluated at $60 \mathrm{~min}$, and on days 1,2,3 and 7 after MCAo. In the dose-response study in mice, C57BL/6 mice were anesthetized and received $1 \mathrm{~h}$ MCAo by intraluminal suture. LAU-0901 (15, 30, $60 \mathrm{mg} / \mathrm{kg} ; n=7-9)$ or vehicle $(n=8)$ was given i.p. at $1 \mathrm{~h}$ after onset of MCAo. Local cerebral blood flow (LCBF) was measured at 1, 2, 4, and $6 \mathrm{~h}$ after MCAo in mice. LAU-0901 treated rats showed improved neurological score throughout the 7-day survival period. LAU-0901 treatment (30,60 and $90 \mathrm{mg} / \mathrm{kg}$ ) reduced total corrected infarct volume compared to vehicle rats by 76,88 and $90 \%$, respectively. Mice treated with LAU-0901 (30 and $60 \mathrm{mg} / \mathrm{kg}$ ) reduced total infarction by $29 \%$ and $66 \%$, respectively. LCBF was improved by treatment with LAU-0901 $(30 \mathrm{mg} / \mathrm{kg})$ by $77 \%$ of baseline at $6 \mathrm{~h}$. In conclusion, we demonstrate for the first time that LAU-0901 improves behavioral scores, LCBF and reduces infarct volume after focal cerebral ischemia in rats and mice. Thus, this PAF receptor antagonist exhibits potent and sustained neuroprotection that may be of value for the design of stroke therapies.
\end{abstract}

(c) 2008 Elsevier Inc. All rights reserved.

\section{Introduction}

Stroke is a major cause of death and disability. Only one drug is approved for clinical use in stroke: a recombinant tissue plasminogen activator, thrombolytic - which is effective in about $4 \%$ of patients who suffer an acute ischemic stroke. The need to develop an effective treatment for stroke, therefore, remains paramount.

Platelet-activating factor (PAF, 1-O-alkyl-2-acetyl-sn-glycero-3-phosphocholine) is a potent phospholipid mediator of leukocyte functions, platelet aggregation and pro-inflammatory signaling. PAF accumulates in response to cell injury, including cerebral ischemia-reperfusion. During ischemia, PAF increases and then becomes a pro-inflammatory messenger as well as a mediator of neurotoxicity (Mukherjee et al., 1999; Chen and Bazan, 2005). Excessive PAF promotes neuronal damage; inhibition of this process plays a critical role in neuronal survival and prevention of ischemic brain injury (Aspey et al., 1997; Tian and Bazan, 2005; Bozlu et al., 2007).

LAU-0901 (2,4,6-Trimethyl-1, 4-dihydro-pyridine-3, 5-dicarboxylic acid) is a highly potent and selective PAF antagonist (Fig. 1) that inhibits

\footnotetext{
* Corresponding author. LSUHSC Neuroscience Center of Excellence 2020 Gravier Str, Suite 9B4, Room 946A New Orleans, LA 70112, USA. Fax: +1 5045990488

E-mail address: lbelay@lsuhsc.edu (L. Belayev).
}

apoptosis, represses the chemotaxis of inflammatory cells, protects photoreceptors from light-induced oxidative stress, and inhibits inflammatory responses in retinal, corneal and neural cells (Bazan et al., 2003; Cortina et al., 2005; He and Bazan, 2006; Boetkjaer et al., 2007). However, LAU-0901 has not been studied in experimental models of focal cerebral ischemia. The doses of LAU-0901 were chosen from our previous studies. The dose-response study in vitro showed significant inhibition of amyloid- and cytokine-induced COX-2 RNA levels by LAU0901 at concentrations of $100 \mathrm{nM}$ (Boetkjaer et al., 2007), and the in vivo study of the light-induced retinal damage (Cortina et al., 2005) used a dose of $30 \mathrm{mg} / \mathrm{kg}$ of LAU-0901, which was highly neuroprotective in rats. Thus, the present study was conducted to assess whether LAU-0901 would show neuroprotective efficacy when administered in different doses after middle cerebral artery occlusion (MCAo) in rats and mice.

\section{Materials and methods}

\section{Animal preparation}

Forty male Sprague-Dawley rats (Charles River Lab., Wilmington, MA) weighing 280-360 g were fasted overnight but allowed free access to water. All studies were approved by the Institutional Animal Care and 
Use Committee of Louisiana State University Health Science Center. Rats were anesthetized with isoflurane (3.5\% for induction, $1 \%$ for maintenance), $70 \%$ nitrous oxide and a balance of oxygen, intubated $(2.1 \mathrm{~mm}$ O.D. $\times 45 \mathrm{~mm}$ B\&D Insyte catheter tubing, Becton Dickinson Infusion Therapy Systems Inc., Sandy, UT) and mechanically ventilated with a rodent respirator (Stoelting Co., Wood Dale, IL). Animals were immobilized with pancuronium bromide $(0.75 \mathrm{mg} / \mathrm{kg}$ i.v., and $0.35 \mathrm{mg} / \mathrm{kg}$ i.v. every half-hour), and atropine $(0.15 \mathrm{mg} / \mathrm{kg}$ i.p.) was administered to diminish secretions. Rectal (CMA/150 Temperature Controller, CMA/ Microdialysis AB, Stockholm, Sweden) and cranial (left temporalis muscle) (Omega Engineering, Stamford, CT) temperatures were monitored and maintained at $36.0 \pm 0.5{ }^{\circ} \mathrm{C}$ during surgical procedure.

\section{Middle cerebral artery occlusion in rats}

The right middle cerebral artery (MCA) was occluded for $2 \mathrm{~h}$ by a modification (Belayev et al., 1996) of the intraluminal-suture occlusion method (Zea Longa et al., 1989), in which a nylon filament is introduced retrogradely into the MCA. In this method, the right common carotid artery was first exposed and the occipital branches of the external carotid artery (ECA) were coagulated. A3-0 monofilament nylon suture was then passed via the proximal ECA into the internal carotid artery and, thence, into the MCA, a distance of $20-22 \mathrm{~mm}$ from the carotid bifurcation according to the animal's weight (Belayev et al., 1996). Prior to use, the suture was coated with poly-L-lysine solution in order to enhance its adhesion to the surrounding endothelium and increase the reproducibility of the resulting infarct (Belayev et al., 1996). The neck incision was then closed. Animals were allowed to awaken from anesthesia and, at 60 min of MCAo, were tested on a standardized neurobehavioral battery (Belayev et al., 1996) to confirm the presence of a high-grade neurological deficit. Rats that did not demonstrate an initial left upper extremity paresis were excluded from further study. After $2 \mathrm{~h}$ of MCAo, rats were re-anesthetized, temperature probes were reinserted, and the intraluminal suture was carefully removed. Incisions were closed and rats were returned to their cages. After surgery rats were observed carefully for signs of discomfort; no such signs were observed.

\section{Middle cerebral artery occlusion in mice}

Male C57BL/6 mice (Charles River Lab., Wilmington, MA) weighing 20-25 g were anesthetized with $2 \%$ halothane, $70 \%$ nitrous oxide and a balance of oxygen using a face mask. The body temperature (CMA/150 Temperature Controller, CMA/Microdialysis AB, Stockholm, Sweden) was monitored and maintained at $37.0 \pm 0.5{ }^{\circ} \mathrm{C}$ during surgical procedure. The right MCA was occluded for $1 \mathrm{~h}$ by the intraluminalfilament method as previously described (Marcheselli et al., 2003). A monofilament suture was introduced retrogradely into the right external carotid artery and advanced into the internal carotid artery and MCA at a distance of 9-10 $\mathrm{mm}$ from the carotid bifurcation. After $1 \mathrm{~h}$ of MCAo, mice were re-anesthetized, the nylon suture was removed, and animals were allowed to survive for $48 \mathrm{~h}$.

Local cerebral blood flow (LCBF) was monitored by laser Doppler flowmetry (Periflux System 5000; Perimed Inc, Sweden) throughout the whole experiment. The laser Doppler probe was attached to the

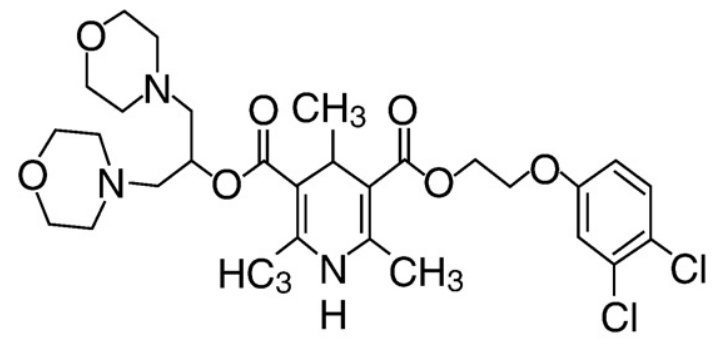

Fig. 1. Chemical structure of LAU-0901.

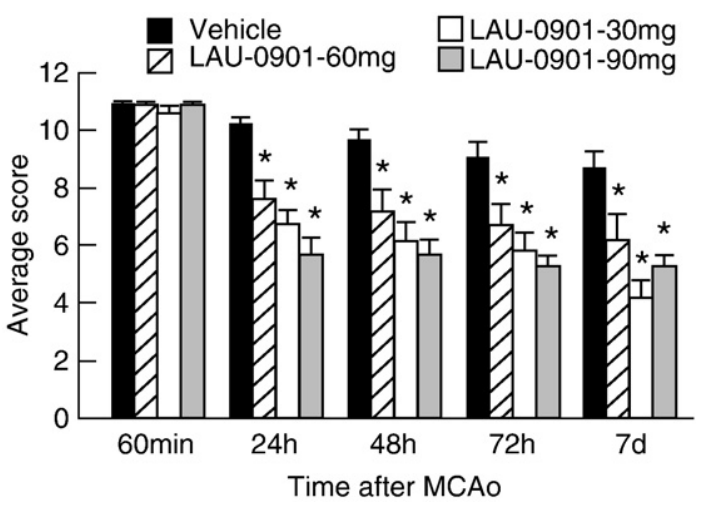

Fig. 2. Total neurological score (normal score $=0$; maximal score $=12$ ) in rats during MCAo ( $1 \mathrm{~h})$ and at various survival times after MCAo. LAU-0901 or vehicle treatments were administered at $2 \mathrm{~h}$ after onset of ischemia. All doses of LAU-0901 significantly improved the neurological score at 24, 48, $72 \mathrm{~h}$ and 7 days compared to vehicle group. Values shown are means \pm SEM. *Significantly different from corresponding vehicle group $(p<0.05)$.

skull $2 \mathrm{~mm}$ posterior and $6 \mathrm{~mm}$ lateral to bregma for continuous monitoring of LCBF in the MCA territory. Occlusion of the MCA was confirmed by documenting a $>80 \%$ decline in relative cerebral blood flow. A return to $50 \%$ of baseline LCBF within 10 min of suture withdrawal confirmed a reperfusion of the MCA territory. Mice that did not meet both ischemic and reperfusion flow criteria were excluded from the study. To examine the effect of LAU-0901 or vehicle treatment on the LCBF, it was continuously monitored and recorded before MCAo, during 60 min of MCAo, and after reperfusion (at 1, 2, 4, and $6 \mathrm{~h}$ ).

\section{Treatment and experimental groups}

The agents (LAU-504; 15, 3060 or $90 \mathrm{mg} / \mathrm{kg}$ ) or vehicle $(45 \%$ cyclodextran, $1 \mathrm{ml} / \mathrm{kg}$ ) was administered i.p. at the time of reperfusion, i.e., $2 \mathrm{~h}$ from onset of MCAo in rats and $1 \mathrm{~h}$ from onset of MCAo in mice.

Rats and mice were randomly assigned to the following groups after MCAo:

Dose-response study in rats: (1) vehicle: $45 \%$ cyclodextran $(n=11)$;

(2) LAU-0901, $30 \mathrm{mg} / \mathrm{kg}(n=9)$; (3) LAU-0901, $60 \mathrm{mg} / \mathrm{kg}(n=10)$ and

(4) LAU-0901, $90 \mathrm{mg} / \mathrm{kg}(n=10)$.

Dose-response study in mice: (1) vehicle: $45 \%$ cyclodextran $(n=8)$;

(2) LAU-0901, $15 \mathrm{mg} / \mathrm{kg}$ ( $n=7)$; (3) LAU-0901, $30 \mathrm{mg} / \mathrm{kg}(n=9)$ and

(4) LAU-0901, $60 \mathrm{mg} / \mathrm{kg}(n=7)$.

LCBF study in mice: LAU-0901, $30 \mathrm{mg} / \mathrm{kg}(n=11)$, and vehicle $(n=8)$.

\section{Neurobehavioral evaluation in rats}

A standardized battery of behavioral tests (Belayev et al., 1996) was used to quantify sensorimotor neurological function in all 40 rats before MCAo, at 60 min after MCAo, and at 24, 48, $72 \mathrm{~h}$ and 7 days after treatment. The battery consisted of 2 tests used to evaluate neurological function: (1) a postural reflex test, to examine upper body posture while the animal is suspended by the tail (Bederson et al., 1986); and (2) a forelimb placing test, to examine sensorimotor integration in forelimb placing responses to visual, tactile and proprioceptive stimuli (De Ryck et al., 1989). Neurological function was graded on a scale of $0-12$ (normal score $=0$, maximal score $=12$ ) as previously described (Belayev et al., 1996). Tests were conducted by an observer blinded to the treatment groups.

\section{Neurobehavioral evaluation in mice}

Mice were examined for neurological deficits on days 1 and 2 after MCAo using a modified five-point Bederson scale (Bederson et al., 
1986). Normal motor function was scored as 0, failure to extend left forepaw as 1 , circling to the contralateral side as 2 , lack of coordination as 3 , and no spontaneous motor activity as 4 .

\section{Histopathology in rats}

Following a 7-day survival, animals were deeply anesthetized with isoflurane and perfused transcardially with isotonic saline for $5 \mathrm{~min}$ followed by fixation with $4 \%$ paraformaldehyde for $20 \mathrm{~min}$. Tenmicron-thick sections were cut in the coronal plane and stained with hematoxylin and eosin. To measure infarct size, histological sections were digitized $\left(\mathrm{MCID}^{\mathrm{TM}}\right.$ Core imaging software, InterFocus Imaging Ltd, Linton, Cambridge, UK) at 7 standardized coronal levels (bregma levels: $+2.7,+1.2,-0.3,-1.3,-1.8,-3.8$ and $-5.0 \mathrm{~mm}$ ) (Konig and Klippel, 1963). An investigator blinded to the experimental groups outlined cortical and subcortical (striatal) infarct areas (which were clearly demarcated) as well as the left- and right-hemisphere contours at each level. The corresponding tissue volumes were calculated by numeric integration of the areas from all sections using Simpson's method (Zhao et al., 1996). Infarct volume was corrected for changes in tissue water content (swelling) by applying the following formula:

$A_{\text {corrected }}=A_{\text {infarct }} \times\left(1-\frac{A_{\mathrm{I}}-A_{\mathrm{C}}}{A_{\mathrm{C}}}\right)$

where $A_{\mathrm{I}}$ is the ipsilateral hemisphere area and $A_{\mathrm{C}}$ is the contralateral hemisphere area (Belayev et al., 2003).

\section{Histopathology in mice}

Mice were allowed to survive for $48 \mathrm{~h}$ after MCAo with free access to food and water, then they were re-anesthetized with sodium pentobarbital. Brains were removed and placed in a freezer at $-20{ }^{\circ} \mathrm{C}$ for up to $20 \mathrm{~min}$ to facilitate sectioning. Two-millimeter-thick coronal sections were cut 2, 4, 6, 8 and $10 \mathrm{~mm}$ from the frontal pole using a brain matrix.
The sections were put in a glass Petri dish containing 2\% TTC solution (2,3,5-triphenyltetrazolium chloride). The dishes were covered with aluminum foil to prevent exposure to light and incubated at $37{ }^{\circ} \mathrm{C}$ for $15 \mathrm{~min}$. The TTC solution was then replaced with $10 \%$ buffered formalin. The sections were photographed for quantitative histopathology. The areas of right hemisphere, left hemisphere, and infarction were measured using NIH image public domain software (version 1.63) by an investigator blinded to the study groups. The volumes of right and left hemispheres and infarction were calculated according to the slice thickness of $2 \mathrm{~mm}$ per slice, and infarct volume was corrected for swelling as described (Doerfler et al., 2001). From these data, total infarction (expressed as a percentage of the contralateral hemisphere) was computed.

\section{Statistical analysis}

Data are presented as mean values \pm SEM. Neurobehavioral scores and infarct size data were analyzed by repeated-measures analysis of variance (ANOVA) with post hoc Bonferroni tests. Physiological variables were compared by Student $t$ tests. Differences at $p<0.05$ were considered statistically significant.

\section{Results}

\section{Physiological variables}

There were no significant differences with respect to rectal and cranial temperatures among the rat and mice experimental groups. Vehicletreated rats lost $\sim 8-13 \%$ of body weight during the 7-day survival period. On the other hand, animals treated with LAU-0901 (60 mg and $90 \mathrm{mg}$ ) lost $\sim 2-7 \%$ of body weight and returned to baseline on day 7 .

\section{Neurological assessment}

All rats had a total neurological score of 0 prior to ischemia; and all animals developed a high-grade neurological deficit (11; maximum
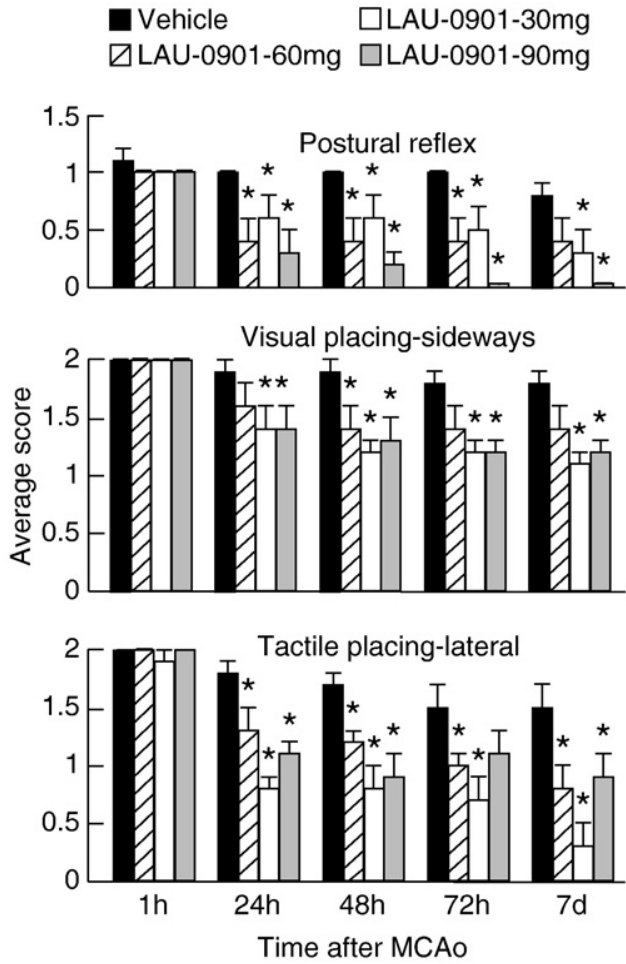
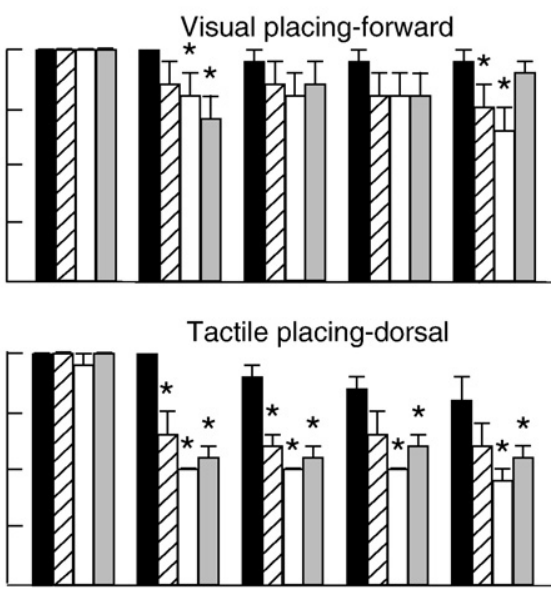

Proprioceptive placing

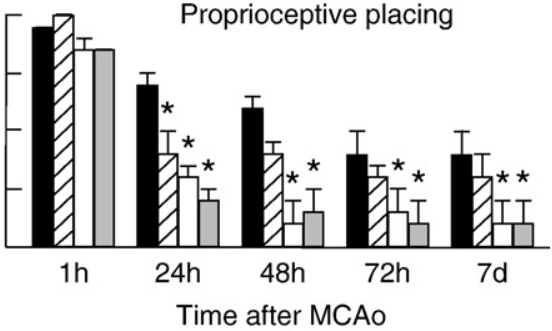

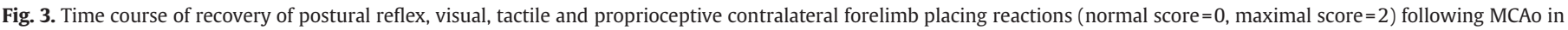

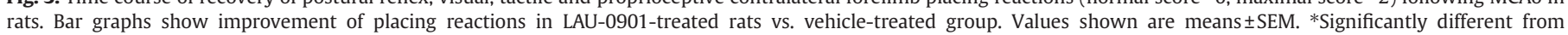
corresponding vehicle group $(p<0.05)$. 

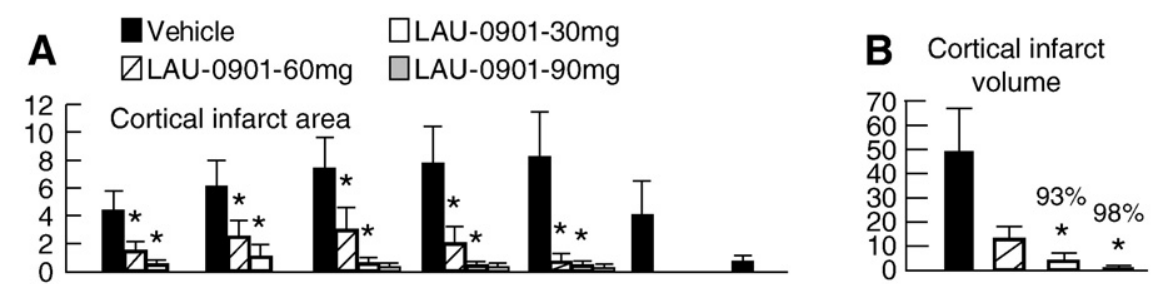

D
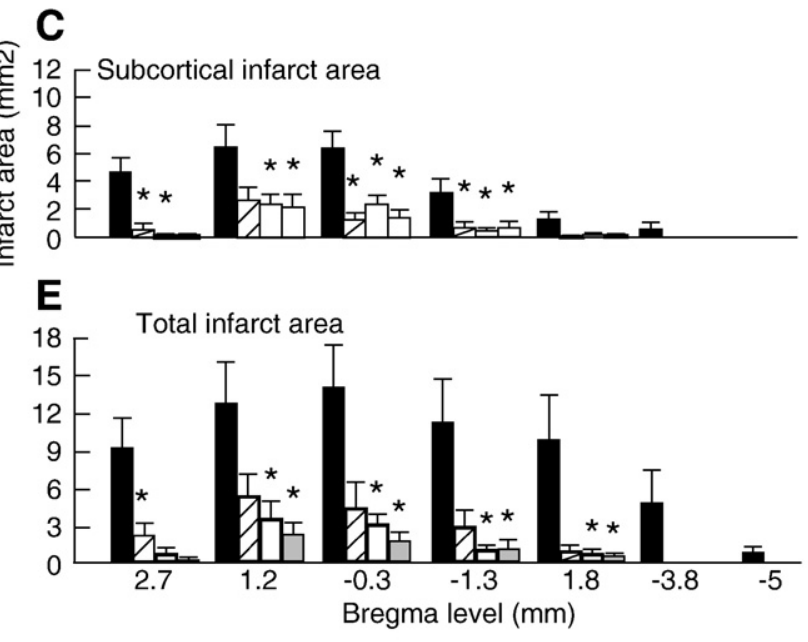

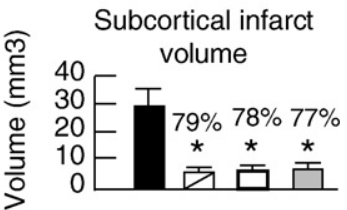

$\mathbf{F}$

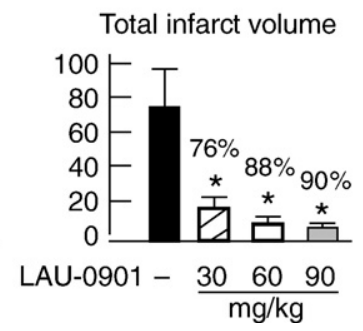

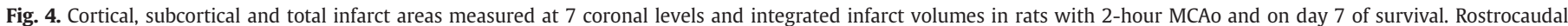

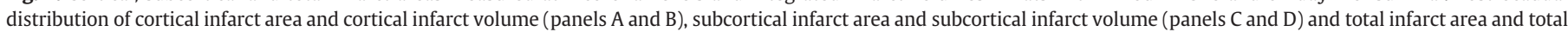
corrected infarct volume (panels E and F) in all groups. Data are presented as mean \pm SEM. *Significantly different from corresponding vehicle group ( $p<0.05$ ).

possible, 12) when examined at 60 min of MCAo (Fig. 2); thus, no animals required exclusion on the basis of an inadequate degree of cerebral ischemia during the neurological assessment. Vehicle-treated animals continued to exhibit severe behavioral impairments throughout the 7-day survival period. All doses of LAU-0901 significantly improved the neurological score compared with vehicle-treated rats at 24, 48, $72 \mathrm{~h}$ and 7 days (Fig. 2). Fig. 3 depicts significant improvement of postural reflex, visual and tactile placing reactions and proprioceptive placing at different times in LAU-0901 treated rats compared to the vehicle group (Fig. 3). LAU-0901-treated mice showed a significant neurological improvement by $40 \%$ and $51 \%$ at
$48 \mathrm{~h}$ in the LAU-0901 30 and $60 \mathrm{mg} / \mathrm{kg}$-treated groups, compared to the vehicle group. Behavioral scores in LAU-0901-treated group with $15 \mathrm{mg} / \mathrm{kg}$ were not significantly different from the vehicle group.

\section{Histopathology}

The dose-response study in rats revealed that neuroprotection was extensive in neocortex (mean tissue salvage, 93\% and 98\%, respectively, in the 60 and $90 \mathrm{mg} / \mathrm{kg}$ LAU-0901 groups) and spread across multiple coronal levels (Figs. 4A and B). Fig. 4C demonstrates the rostrocaudal distribution of subcortical infarct areas, which were smaller in all LAU-
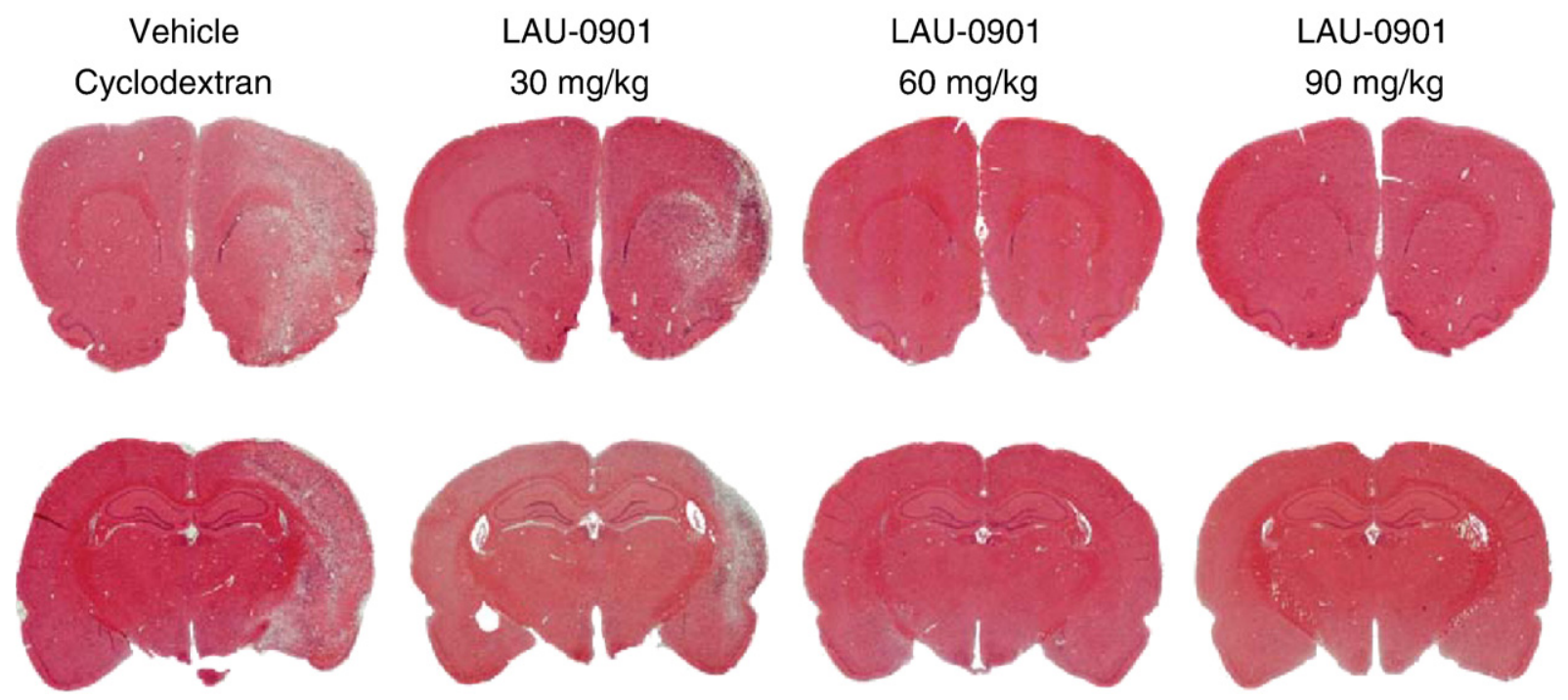

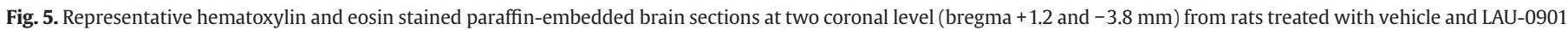

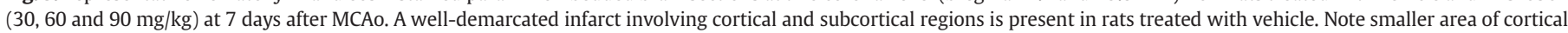

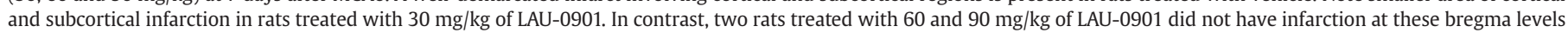
(ZEISS microscope). 
0901 treated groups compared to the vehicle group (Fig. 4C). Mean subcortical infarct volume was also significantly protected by treatment with LAU-0901 (30, 60 and $90 \mathrm{mg} / \mathrm{kg}$ ) by $79 \%, 78 \%$ and $77 \%$, respectively (Fig. 4D). Treatment with LAU-0901 markedly reduced total (cortical + subcortical) infarct areas compared to the vehicle group (Fig. 4E). Total infarct volume corrected for brain swelling was reduced by a mean of $76 \%, 88 \%$ and $90 \%$, respectively by treatment with LAU-0901 in the 30,60 and $90 \mathrm{mg} / \mathrm{kg}$ groups (Fig. 4F). The brains of vehicle-treated animals with MCAo exhibited a consistent pannecrotic lesion involving both cortical and subcortical (mainly striatal) regions of the right hemisphere, characterized microscopically by loss of neuronal, glial, and vascular elements. By contrast, infarct size was dramatically reduced by all doses of LAU-0901 therapy (Fig. 5).

In the dose-response study in mice, we measured the extent of neuroprotection achieved with 30 and $60 \mathrm{mg} / \mathrm{kg}$ of LAU-0901, when administered at $1 \mathrm{~h}$ after onset of MCAo (Fig. 6). Infarct volume, expressed as percentage of the corrected infarct volume in the ipsilateral hemispheric volume, was significantly reduced by $29 \%$ and $66 \%$ in the LAU-0901 30 and $60 \mathrm{mg} / \mathrm{kg}$-treated groups, compared to the vehicle group. Infarct volume was not significantly different between LAU-0901 (15 mg/kg) and the vehicle-treated group.

LCBF decreased immediately after MCAo to $15 \%$ of basal and remained decreased during 60 min of occlusion in two groups (Fig. 7). Ten minutes after suture withdrawal, LCBF increased to $50 \%$ of basal, remained at the same level during the next $2 \mathrm{~h}$, and then gradually decreased to $41 \%$ in the vehicle-treated group at $6 \mathrm{~h}$. In contrast, LCBF continually increased in mice treated with LAU-0901 (by 77\%) of basal at $6 \mathrm{~h}$, compared to the vehicle-treated group (Fig. 7).

Eight animals died in our study: 3 rats in the vehicle group (died on days 2, 3 and 4); 2 rats in the LAU-0901 $30 \mathrm{mg} / \mathrm{kg}$ group (died on days 2 and 6) and 3 rats in the LAU-0901 $60 \mathrm{mg} / \mathrm{kg}$ group (died on days 3, 5 and 6). No animal died in the LAU-0901 $90 \mathrm{mg} / \mathrm{kg}$ group and in doseresponse and LCBF studies in mice.

\section{Discussion}

We have shown here for the first time that the novel PAF receptor antagonist, LAU-0901, confers robust neuroprotection in a widely used, reproducible experimental model of focal cerebral ischemia. Our results demonstrate that treatment with LAU-0901, when applied immediately after reperfusion following a 2-hour focal ischemic insult reduces the volume of cerebral infarction and improves the neurological score compared to the vehicle group.

$\mathrm{PAF}$ is a membrane-derived bioactive phospholipid that has been suggested to play an important role in brain ischemia and stroke (Bazan,

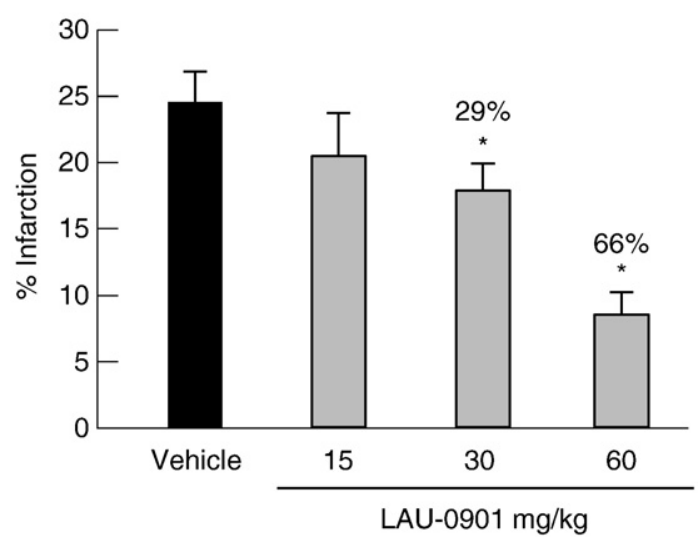

Fig. 6. Dose-response study in mice. Infarct volume, expressed as percentage of the corrected infarct volume in the ipsilateral hemispheric volume, was significantly lower in LAU-treated mice (30 and $60 \mathrm{mg} / \mathrm{kg}$ ), as compared to the vehicle-treated group. Values shown are means \pm SEM. *Significantly different from corresponding vehicle group $(p<0.05)$.

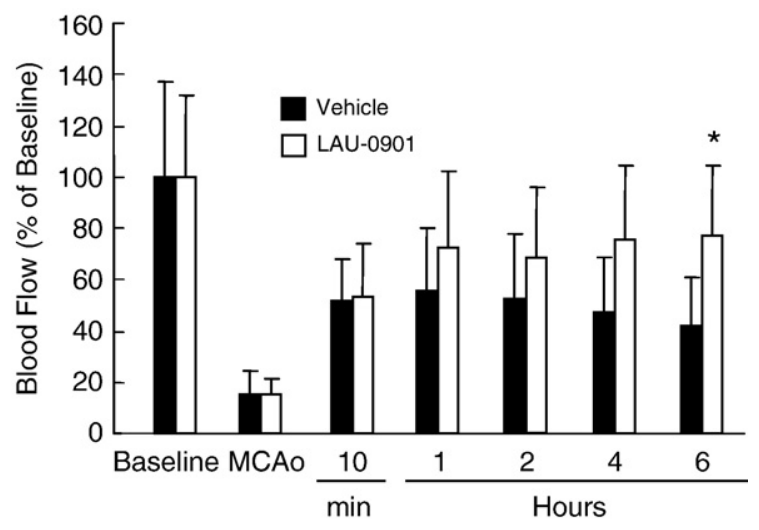

Fig. 7. Effect of LAU-0901 on local cerebral blood flow (LCBF). Basal indicated no MCAo. LAU-0901 (30 mg/kg; $n=11)$ or vehicle $(n=8)$ was administered IP at $1 \mathrm{~h}$ after onset of reperfusion. LCBF was reduced to $15 \%$ during MCAo in all animals and increased to $41 \%$ from baseline in vehicle-treated mice. In contrast, treatment with LAU-0901 increased LCBF to $77 \%$ at $6 \mathrm{~h}$ compared to vehicle-treated mice. Values shown are means \pm SEM. *Significantly different from corresponding vehicle group $(p<0.05)$.

2003). While basal levels of PAF are virtually undetectable in resting tissues, PAF is rapidly synthesized in the brain during ischemia, mediates the release of the neurotransmitter glutamate in the hippocampus, and selectively activates a network of early response gene expression, including the rapid induction of COX-2 and TNF $\alpha$ (Cui et al., 2007; He and Bazan, 2006). During ischemia the rates of PAF synthesis and degradation no longer maintain a modulated PAF pool size; PAF then accumulates and becomes a pro-inflammatory messenger and a mediator of neurotoxicity (Bazan, 2005). PAF levels are increased in gerbil brains in response to $5 \mathrm{~min}$ of bilateral carotid occlusion at early stages of reperfusion, and the naturally occurring PAF antagonist, BN 52021, has been shown to be neuroprotective in this model (Panetta et al., 1989).

We have previously shown that PAF is involved in synaptic plasticity and memory formation (Kato et al., 1994). Infusion of PAF into specific brain regions promotes memory facilitation in rats. In these experiments using the step-down inhibitory avoidance or spatial-habitation task, when PAF was infused $10 \mathrm{~min}$ before or immediately after training, animal retention scores were enhanced (Izquierdo et al., 1995). However, when PAF infusion was delayed for 60 min after training, no effect on retention was observed. The role of PAF in hippocampal synaptic plasticity and memory storage was demonstrated using mice deficient in PAF receptor, in which reduced long-term potentiation (LTP) was detected (Chen et al., 2002).

PAF antagonists, after ischemia and reperfusion, has been shown to be beneficial in different animal models: myocardial reperfusion injury in swine (Loucks et al., 2000), lung ischemia-reperfusion injury in canine (Iwazaki et al., 2001), intestinal ischemia-reperfusion in mouse (Souza et al., 2003), acute hepatic injury in rat (Grypioti et al., 2008) and renal ischemia in rat (Lloberas et al., 2001).

Also, the neuroprotective effect of PAF inhibitors on neonatal rat model has been demonstrated in hypoxic ischemic brain injury (Bozlu et al., 2007), global cerebral ischemia in gerbils (Panetta et al., 1989) and focal cerebral ischemia in rat (Aspey et al., 1997) and mouse (Subbanna and Tyagi, 2006).

Unfortunately, a number of experimental stroke drugs have been proved ineffective in human trials (for review, see O'Collins et al., 2006). The possibility that species-related and even strain-related differences may also play a role cannot be ruled out. It is well known that the same surgical procedure for focal cerebral ischemia may produce very different neuropathological outcomes in mice and rats. For this reason, we established a dose-response relationship for neuroprotection elicited by of LAU-0901 in both rat and mouse models of focal cerebral ischemia. The high degree of histological protection was demonstrated with all doses of LAU-0901 in rats. Vehicle-treated animals showed a large cortical and subcortical infarct at multiple 
coronal levels. By contrast, LAU-0901 treated rats significantly reduced cortical (by 93-98\%), subcortical (77-79\%) and total infarct volumes (by 76-90\%) compared to the vehicle group. The most remarkable effect of LAU-0901 in rat study was found in the 60 and $90 \mathrm{mg} / \mathrm{kg}$ LAU0901 treated groups. Mice treated with 30 and $60 \mathrm{mg} / \mathrm{kg}$ of LAU-0901 showed reduced total infarction, but not with $15 \mathrm{mg} / \mathrm{kg}$.

The neuroprotective mechanism of LAU-0901 against focal cerebral ischemia is not completely understood. We have previously shown that PAF produces cerebral damage by stimulating leukocyte infiltration in damaged neuronal tissue, increasing intracellular calcium concentration, disrupting the blood-brain barrier, and reducing cerebral blood flow (Bazan, 2005). The recovery of LCBF after $1 \mathrm{~h}$ of MCAo was remarkable in LAU-0901-treated mice. In contrast to the vehicle-treated group, LCBF continually increased in mice treated with LAU-0901 (by 77\%) of baseline at $6 \mathrm{~h}$. Cerebral blood flow improvement is therefore a likely explanation for the smaller infarction in the cortical and, especially, in subcortical area, which is usually very resistant to therapeutic interventions. Further studies are needed to investigate the exact mechanism by which LAU0901 protects the brain after focal cerebral ischemia.

Functional deficits in rodents due to MCAo represent approximately the outcome in patients. Stroke produced by focal cerebral ischemia is commonly associated with impaired sensorimotor and cognitive function. Approximately $70 \%$ to $80 \%$ of all patients experience hemiparesis immediately after stroke. After MCAo, rodents also exhibit a behavioral deficit characterized by sensorimotor dysfunction. We have shown here that administration of all three doses of LAU-0901 significantly improved the neurological score compared with vehicle through the 7-day survival period. There were no adverse behavioral side effects observed with LAU-0901 administration.

The beneficial effect of LAU-0901 has been shown in a well-controlled animal model of MCAo in rats (Belayev et al., 1996). Intraluminal-suture occlusion of the MCA has become increasingly popular as a focal ischemia model because of its relative simplicity and minimally invasive nature. In the present study and in recently published observations, we have used a poly-L-Lysine-coated suture and have found that this technique leads to reliable and highly consistent results (coefficient of variation of infarct volume, 9\%) (Belayev et al., 1996). It produces consistent cortical plus subcortical infarct that closely mimics in extent and severity the large hemispheric infarcts resulting from proximal MCA and internal carotid artery occlusions in humans. Essential to the consistency of the model is the close monitoring body and cranial temperatures. Cranial temperature control is extremely important, as it is an essential determinant of the extent of brain injury (Ginsberg and Busto, 1998).

In summary, our results have shown for the first time that the novel the PAF inhibitor, LAU-0901 (systemically administered), is markedly neuroprotective in acute focal cerebral ischemia in rat and mice, both improving behavioral function and reducing the extent of histological damage with a therapeutic window of at least $2 \mathrm{~h}$.

\section{Acknowledgments}

This investigation was supported by NIH Grant NS23002 (NGB). The authors thank George Asberry for the technical assistance.

\section{References}

Aspey, B.S., Alp, M.S., Patel, Y., Harrison, M.J., 1997. Effects of combined glutamate and platelet-activating factor inhibition on the outcome of focal cerebral ischaemia - an initial screening study. Metab. Brain Dis. 12, 237-249.

Bazan, N.G., 2003. Synaptic lipid signaling: significance of polyunsaturated fatty acids and platelet-activating factor. J. Lipid Res. 44, 2221-2233.

Bazan, N.G., 2005. Lipid signaling in neural plasticity, brain repair, and neuroprotection. Mol. Neurobiol. 32, 89-103.

Bazan, N.G., Sunkel, C., Marcheselli, V.L., Builla, G.J., 2003. Assignee Louisiana State University, 2003. 2,4,6-trimethyl-1,4-dihydro-pyridine-3,5-dicarboxylic acid esters as neuroprotective drugs. US Patent 6,566,359 B1.

Bederson, J.B., Pitts, L.H., Tsuji, M., Nishimura, M.C., Davis, R.L., Bartkowski, H., 1986. Rat middle cerebral artery occlusion: evaluation of the model and development of a neurologic examination. Stroke 17, 472-476.
Belayev, L., Alonso, O.F., Busto, R., Zhao, W., Ginsberg, M.D., 1996. Middle cerebral artery occlusion in the rat by intraluminal suture. Neurological and pathological evaluation of an improved model. Stroke 27, 1616-1622.

Belayev, L., Khoutorova, L., Deisher, T.A., Belayev, A., Busto, R., Zhang, Y., Zhao, W., Ginsberg M.D., 2003. Neuroprotective effect of SolCD39, a novel platelet aggregation inhibitor, on transient middle cerebral artery occlusion in rats. Stroke 34, 758-763.

Boetkjaer, A., Boedker, M., Cui, J.G., Zhao, Y., Lukiw, W.J., 2007. Synergism in the repression of COX-2- and TNFalpha-induction in platelet activating factor-stressed human neural cells. Neurosci. Lett. 426, 59-63.

Bozlu, G., Atici, A., Turhan, A.H., Polat, A., Nayci, A., Okuyaz, C., Taskinlar, H., 2007. Plateletactivating factor antagonist (ABT-491) decreases neuronal apoptosis in neonatal rat model of hypoxic ischemic brain injury. Brain Res. 1143, 193-198.

Chen, C., Bazan, N.G., 2005. Lipid signaling: sleep, synaptic plasticity, and neuroprotection. Prostaglandins Other Lipid Mediat. 77, 65-76.

Chen, C., Magee, J.C., Bazan, N.G., 2002. Cyclooxygenase-2 regulates prostaglandin E2 signaling in hippocampal long-term synaptic plasticity. J. Neurophysiol. 87, 2851-2857.

Cortina, M.S., Gordon, W.C., Lukiw, W.J., Bazan, N.G., 2005. Oxidative stress-induced retinal damage up-regulates DNA polymerase gamma and 8-oxoguanine-DNAglycosylase in photoreceptor synaptic mitochondria. Exp. Eye Res. 81, 742-750.

Cui, J.G., Hill, J.M., Zhao, Y., Lukiw, W.J., 2007. Expression of inflammatory genes in the primary visual cortex of late-stage Alzheimer's disease. Neuroreport 18, 115-119.

De Ryck, M. Van Reempts, J., Borgers, M., Wauquier, A., Janssen, P.A., 1989. Photochemical stroke model: flunarizine prevents sensorimotor deficits after neocortical infarcts in rats. Stroke 20,1383-1390.

Doerfler, A., Schwab, S., Hoffmann, T.T., Engelhorn, T., Forsting, M., 2001. Combination of decompressive craniectomy and mild hypothermia ameliorates infarction volume after permanent focal ischemia in rats. Stroke 32, 2675-2681.

Ginsberg, M.D., Busto, R., 1998. Combating hyperthermia in acute stroke: a significant clinical concern. Stroke 29, 529-534.

Grypioti, A.D., Kostopanagiotou, G., Demopoulos, C.A., Roussos, A., Mykoniatis, M., 2008 Platelet activating factor (PAF) antagonism with ginkgolide B protects the liver against acute injury. Importance of controlling the receptor of PAF. Dig. Dis. Sci. 53, 1054-1062.

He, J., Bazan, H.E., 2006. Synergistic effect of platelet-activating factor and tumor necrosis factor-alpha on corneal myofibroblast apoptosis. Invest. Ophthalmol. Vis Sci. 47, 883-891.

Iwazaki, S., Takeyoshi, I., Ohwada, S., Sunose, Y., Aiba, M., Tsutsumi, H., Kawashima, Y., Matsumoto, K., Morishita, Y., 2001. FR128998 (a PAF receptor antagonist) counters the increased pulmonary vascular resistance associated with ischemia-reperfusion injury in the canine lung. Int. J. Angiol. 10, 10-14.

Izquierdo, I., Fin, C., Schmitz, P.K., Da Silva, R.C., Jerusalinsky, D., Quillfeldt, J.A. Ferreira, M.B., Medina, J.H., Bazan, N.G., 1995. Memory enhancement by intrahippocampal, intraamygdala, or intraentorhinal infusion of platelet-activating factor measured in an inhibitory avoidance task. Proc. Natl. Acad. Sci. U. S. A. 92, 5047-5051.

Kato, K., Clark, G.D., Bazan, N.G., Zorumski, C.F., 1994. Platelet-activating factor as a potential retrograde messenger in CA1 hippocampal long-term potentiation. Nature. 367, 175-179.

Konig, J.F.R., Klippel, R.A., 1963. The Rat Brain: a Stereotaxic Atlas of the Forebrain and Lower Parts of the Brain Stem. Lippincott Williams and Wilkins, Baltimore.

Lloberas, N., Cruzado, J.M., Torras, J., Herrero-Fresneda, I., Riera, M., Merlos, M., Grinyó J.M., 2001. Protective effect of UR-12670 on chronic nephropathy induced by warm ischaemia in ageing uninephrectomized rats. Nephrol. Dial. Transplant 16, 735-741.

Loucks, E.B., Qayumi, A.K., Godin, D.V., English, J.C., Lim, S.P., Al Mahmeed, T., Gul, S. 2000. Therapeutic potential of platelet-activating factor antagonism in the management of myocardial infarction. Can. J. Cardiol. 16, 497-504.

Marcheselli, V.L., Hong, S., Lukiw, W.J., Tian, X.H., Gronert, K., Musto, A., Hardy, M., Gimenez, J.M., Chiang, N., Serhan, C.N., Bazan, N.G., 2003. Novel docosanoids inhibit brain ischemia-reperfusion-mediated leukocyte infiltration and pro-inflammatory gene expression. J. Biol. Chem. 278, 43807-43817.

Mukherjee, P.K., DeCoster, M.A., Campbell, F.Z., Davis, R.J., Bazan, N.G., 1999. Glutamate receptor signaling interplay modulates stress-sensitive mitogen-activated protein kinases and neuronal cell death. J. Biol. Chem. 274, 6493-6498.

O'Collins, V.E., Macleod, M.R., Donnan, G.A., Horky, L.L., van der Worp, B.H., Howells, D. W., 2006. 1,026 experimental treatments in acute stroke. Ann. Neurol. 59, 467-477.

Panetta, T., Marcheselli, V.L., Braquet, P., Bazan, N.G., 1989. Arachidonic acid metabolism and cerebral blood flow in the normal, ischemic, and reperfused gerbil brain. Inhibition of ischemia-reperfusion-induced cerebral injury by a platelet-activating factor antagonist (BN 52021). Ann. N. Y. Acad. Sci. 559 340-351.

Souza, D.G., Pinho, V., Soares, A.C., Shimizu, T., Ishii, S., Teixeira, M.M., 2003. Role of PAF receptors during intestinal ischemia and reperfusion injury. A comparative study between PAF receptor-deficient mice and PAF receptor antagonist treatment. Br. J. Pharmacol. 139, 733-740.

Subbanna, P.K., Tyagi, M.G., 2006. PAF antagonism modifies neuroprotective action of histone deacetylase and calcineurin phosphatase inhibitors in mice. Indian J. Exp. Biol. 44, 886-891.

Tian, X., Bazan, N.G., 2005. Neuroprotection by platelet-activating factor antagonism. Ann. N.Y. Acad. Sci. 1053, 455-456.

Zea Longa, E.Z., Weinstein, P.R., Carlson, S., Cummins, R., 1989. Reversible middle cerebral artery occlusion without craniectomy in rats. Stroke 20, 84-91.

Zhao, W., Ginsberg, M.D., Prado, R., Belayev, L., 1996. Depiction of infarct frequency distribution by computer-assisted image mapping in rat brains with middle cerebral artery occlusion. Comparison of photothrombotic and intraluminal suture models. Stroke 27, 1112-1117. 